\title{
Global policies and local norms: sociolinguistic awareness and language choice at an international university
}

\author{
HEDDA SÖDERLUNDH
}

Abstract

As part of the internationalization of higher education, more and more European university courses are being taught in English. Exchanges between universities have grown, and students from different parts of the world now often study together. What does this international environment look like in linguistic terms? Do students and teaching staff speak only the course language English, or are other languages also used, and if so, in what situations and contexts? These questions are discussed on the basis of an ethnographic study of an English-medium university course in Sweden. Extended examples of interaction show that participants adapt their use of languages to place-bound needs and conditions, giving rise to local norms. The national language Swedish holds a special position, as the first language of the majority and the lecturer. The course language English is dominant as a de facto lingua franca, but local social and linguistic needs and conditions leave room for other languages as well. Overall, course participants orient to three competing principles of language use: (a) English as a lingua franca, (b) the speaker's orientation to her or his own language and (c) the special position of Swedish, as the first language of the majority and the lecturer.

Keywords: internationalization; classroom discourse; higher education; English as medium of instruction; multilingualism.

\section{Introduction: a snapshot from a course}

At a university in Sweden, a lecturer is concluding a course in business studies. In the seminar room there are both Swedish and foreign students. The latter come from various European countries, but also from the United States and Canada, and are spending one or two 20 -week terms in the country studying at the department. The medium of instruction is English. 
Throughout the course, language has been an important issue. When the lecturer now informs his students about the forthcoming examination, he says:

There's been a few e-mails about language. I'll just go over it again. You write in whatever language you need to write in, which means for the most of you Swedish or English. ... But if you're writing and you get stuck ... go ahead and blend your language. Okay? If you are French or Spanish or whatever go ahead and (pause) it would be easier for me if you write in English if you're absolutely stuck write in your home language. ... A paragraph makes sense even if you jump through three languages as long as it has a subject and a beginning and an ending and is logical. ... So don't let language make you nervous in the exam. All right? (Teacher, Marketing $0315 \mathrm{v}$ )

The example shows how complex, but also how dynamic, the linguistic situation in an international university course can be. Formally, the medium of instruction is English, and in syllabuses and policy documents this language is presented as the only one used on the course. When the lecturer informs the students about the exam, however, the reality looks rather different. Swedish is mentioned as an important alternative language, and students are also allowed to use French or Spanish in the examination. Furthermore, it is acceptable to mix languages.

The situation described raises questions of linguistic environments and language practices at international universities. What do international courses taught in English look like in linguistic terms? Do students and their teachers speak only the nominal course language English, or are other languages also used? And if they are, in what situations and contexts does that happen? In this article I will discuss these questions on the basis of an ethnographic study of an English-medium university course in Sweden. My observations, combined with close analysis of interactional sequences, will show that the students and teaching staff on the course orient to three competing principles of language use: (a) English as a lingua franca, (b) the speaker's orientation to her or his own language and (c) the special position of the national language Swedish, as the first language of the majority and the lecturer. On the basis of these three principles, or points of reference, local norms arise which participants orient to in their interaction. Although these norms are local, the case of Sweden is not unique. Nevile and Wagner (2008) for example, in a study of a group examination in Denmark, demonstrate that choice of language at an international university is always a relevant issue for participants, while Ljosland (2008) shows that on an English-medium master's program in Norway the national language Norwegian, like Swedish in the present study, holds a special position.

The structure of the article is as follows. Section 2 provides a background concerning the internationalization of higher education and the example of 
Sweden. Section 3 gives an overview of the field of research and the theoretical and methodological starting points of the article. The study combines linguistics and ethnography (cf. Creese 2008), but is also inspired by socio-functional approaches to multilingual communication (cf. for example Gafaranga 2007). Section 4 presents extended examples of use of languages other than English in the course studied, and in Section 5 I discuss the three competing points of reference for language choice that permeate the course in greater depth. Students and lecturers adopt a pragmatic approach, orienting to the linguistic proficiency of other participants, but also to the degree of institutionality of the interaction. In the same section, prior to my concluding remarks, I consider what happens if students violate the jointly established norm.

\section{Background}

\subsection{International universities}

The growing use of English in higher education across Europe is primarily a result of increased mobility and an expansion of exchanges between universities and other higher education institutions in different countries. Exchanges are one of several strategies for moving individual universities towards a global rather than a local context. Teaching in English can be seen as a form of "internationalization at home" and is, as such, an important tool (cf. En högskola $i$ världen 2008: 36). As Graddol (2006) and others point out, universities can no longer be regarded as purely local institutions, but have to be seen as part of a global market. Bull (2006) describes this trend as a change in the basic values of universities (see also Mortensen and Haberland this issue), and Coleman (2006: 3-4) observes that it is also a matter of economics. By introducing a global language into their teaching, universities can broaden their recruitment and boost student numbers. The introduction of English-medium instruction has therefore not uncommonly been compared to a market adjustment albeit to a purely English-speaking market — in the wake of internationalization (see also Greenall in this issue).

Roberts (2008: 9) argues that there is no single type of international university. Multicultural perspectives in syllabuses and policy documents, and course places earmarked for foreign students, are other ways of pursuing internationalization. Internationalization is a dynamic process, and ultimately it is individual stakeholders who determine what goals, strategies and resources are appropriate (Knight 1999: 21). As Montgomery (2008: 20) points out, the results are difficult to measure, and it is problematic to determine when effective internationalization has been achieved. Syllabuses and descriptions stating that courses are taught in English may give the appearance of one 
reality, while actual implementation in the lecture hall and seminar room reveals another.

\subsection{The example of Sweden: teaching in English}

Sweden today offers a comparatively large number of university courses and study programs taught in English. A count of all such programs across Europe puts the country in fourth place, after the Netherlands, Germany and Finland (Wächter and Maiworm 2008: 11). In the year 2009, 18\% of the individual courses and $25 \%$ of the programs were run in English. At master's level 65\% of the programs were taught in English (Salö 2010: 35-36). ${ }^{1}$ Roughly half the students on master's programs were Swedish and half from abroad (Utländska studenter i Sverige 2008: 7).

\section{The field of research}

Language-oriented studies of internationalization in higher education focus above all on the spread and use of the English language. Broadly speaking, such studies can be divided into three categories: (a) surveys of the extent to which English is used on programs and courses (e.g. Coleman 2006; Wächter and Maiworm 2008); (b) studies of how national students interact in their first language, compared with the course language English (e.g. Airey 2009); and (c) studies of English as a lingua franca in seminar rooms and lecture halls (e.g. Mauranen 2003; Björkman 2010; Mortensen 2010). Attention is rarely paid to the potential multilingualism which internationalization entails. The focus on English is not in fact particularly surprising, given that many universities themselves seem to regard the process as monolingual rather than multilingual or multinational (cf. Ljosland 2005).

One exception in the literature is the volume Higher Education in the Global Village (Haberland et al. 2008), published within the CALPIU (Cultural and Linguistic Practices in the International University) network. Among the contributions it includes is the study by Nevile and Wagner (2008) mentioned above. Through conversation analysis (CA), those authors uncover two competing practices regarding language choice: speaking one language only, or speaking the language used by the preceding speaker and hence, as an individual, constantly switching languages (Nevile and Wagner 2008: 154-168). Language choice, the authors observe, is thus not something that can be done "simply and easy, once and for all, and subsequently taken-for-granted, but rather is oriented to by participants throughout, and is dependent on momentto-moment interactional contingencies for speaker designation and participation" (Nevile and Wagner 2008: 168). 
Another exception is Ljosland (2008), who reports on an ethnographic case study of language use on a nominally English-medium master's program in Norway. In that study, Ljosland (2008: 209) shows that lecturers and students have a pragmatic attitude towards the official course language English, adapting their language use to what participants understand and feel comfortable with. In informal oral situations especially, other languages are common, but even in study-related contexts code switching occurs, in particular to Norwegian. Like Nevile and Wagner, Ljosland thus demonstrates that a multilingual environment is constantly present in international university education, though syllabuses and policy documents may describe a different reality.

The present article, like Nevile and Wagner (2008), aims to draw attention to linguistic practices and to make visible norms and attitudes affecting language choice in an international university course, in this case in business studies. As in Ljosland (2008), the method is ethnographic, which distinguishes this investigation from that of Nevile and Wagner. The study forms part of a larger project concerning language use on nominally English-medium courses, and which comprises observations and video recordings from six courses at a Swedish university (see Söderlundh 2010). Here, the focus will be on one of these courses, while observations and lessons learnt from the others will provide a basis for comparison.

\subsection{Ethnographic approach of the study}

As in other studies that combine ethnography and linguistics, my basic assumption is that language, in the form of texts or interactional sequences, is part of a larger social and cultural context, and that knowledge about that context is important in understanding language use (cf. Creese 2008: 232; Rampton 2007). The aim is to offer an "insider's perspective" on processes and events in the environment in question. Blommaert (2007: 682) points out that "good ethnography is iconic of the object it has set out to examine", and that participants' experiences and perceptions should form the basis for the analysis. Throughout, the perspective and the orientation of the participants are important.

The data on which the article is based consist of observations of a business studies course in Sweden, supplemented by audio and video recordings. To see the use of different languages in context, I followed roughly half the lecturerled seminars and participated in a number of study contexts outside the classroom (12 hours of observations in total). In all, six hours of recordings were made. I would argue that these observations, combined with a close analysis of the interaction that took place, allow language use in this setting to be studied from a broader point of view. 


\subsection{Institutional interaction}

Most of the interaction observed and included in my data is institutional in purpose. The participants orient to tasks and identities that are associated with the institution in question (see, for example, Drew and Heritage 1992: 22-25), in this case the teaching and learning of business studies as a university subject. The topic of discussion is almost always business studies, and the participants exhibit either a teacher's or a student's perspective. As will become clear from my analysis of the data, the manifestation of an institutional or non-institutional context affects participants' choices of language.

That alternation of languages can serve as a framework for interaction is well documented in studies that adopt a socio-functional approach to multilingual communication (see, for instance, "situational switching" Gumperz [1982: 98]; “discourse-related code-switching” Auer [1995: 125]). Language choice, or alternation between languages, is regarded as a contextualization cue, i.e. a means by which "speakers signal and listeners interpret what the activity is, how semantic content is to be understood and how each sentence relates to what precedes or follows" (Gumperz 1982: 131). Above all, alternation has a contrastive effect. The use of a language other than English on an English-medium course may signal a specific context or give prominence to other social functions in the interaction. As Gafaranga and Torras (2001) argue, the contrastive function is ultimately dependent on the norms which participants themselves create and on whether they act as if the conversation is being conducted in a "monolingual medium" or a "bilingual medium". Alternation has a particularly marked effect when it violates the jointly established norm for language choice in a given interaction.

In my analysis, I view the use of languages other than English in relation to a broad situational context and whether that context is institutional or not. The situational context is not a fixed part of the environment, but can vary within one and the same interaction, depending on the actions of the participants. Goals, roles and topics often shift between institutional and non-institutional in nature as interactions proceed, and different sequences and phases of seminars not uncommonly differ in character. In the following I will refer to institutional interactional sequences as on-task talk and non-institutional sequences as offtask talk.

\section{Analysis}

In line with the theoretical framework outlined above, I will begin my presentation of the results with a general description of the course environment. After 
that, extended examples will be given of the use of languages in the course, followed by a concluding discussion of the norms, shaping language use, that are made visible in interaction between the participants.

\subsection{Basic conditions for a multilingual environment}

In the English prospectus distributed before the beginning of the term, the university at which I carried out my investigation states that, by providing education in English, it wishes to "enable students from abroad without prior knowledge of Swedish to study at [the university]". The courses offered can thus be seen as a form of what was referred to above as internationalization at home (cf. En högskola $i$ världen 2008: 36), and the university falls within the category of international universities which, according to Roberts (2008: 9), think locally, but act globally. Through the choice of language, courses are aimed at English-speaking students from around the world, but their content, educational approach and syllabuses are still largely national products.

At the time of my observations, the university has no regulations concerning the language of instruction. Likewise, there are no guidelines on Englishmedium teaching or directives on how the university believes that such teaching is best carried out. Instead, each department determines the extent to which English is to be used and the design of the individual courses, and it emerges from the observations made that it is in practice up to individual lecturers to handle language issues of various kinds as they arise in their teaching. Different members of the department's teaching staff in fact apply different strategies: some take the view, for example, that Swedish-speaking students can hand in assignments in Swedish, if the lecturer is Swedish-speaking, while others consider that all work should be written in English, as the course diploma states that students have attended an English-medium course. Actual practice thus differs from one lecturer to another.

The course consists primarily of seminars, i.e. lecturer-led, interactive teaching and learning sessions in which the students are expected to answer questions and discuss assignments given to them by the teacher. The two lecturers teach in English, but have Swedish as their first language. Of the 48 students, 19 are from universities outside Sweden. Most of them come from Englishspeaking countries (the United States, Canada and Australia) and they, together with the majority of the Swedish students, participate actively in the seminars. A group of six exchange students from France and Spain, along with three or four Swedish-speaking students, are relatively quiet. None of them appear to be particularly confident in English and they seem reluctant to talk in the seminar room. 


\subsection{Languages other than English}

Are other languages than English, then, used in connection with teaching? If so, in what situations does this happen, and what are the salient features of these different situations? Do students, for example, speak only English in lecturer-led classes, but other languages in corridors and group study rooms? Or do other languages also occur during seminars? It very soon becomes clear to the observer that the national language Swedish, especially, is also spoken in the course, both within and outside teaching situations. Spanish and French are used as well, but never as a part of seminar teaching.

Below I discuss in detail examples of the situations and contexts in which languages other than English occur. First, I describe language choices in studyrelated contexts involving students with different first languages (Section 4.2.1). I then examine language use in study contexts involving spontaneous groupings in which only a few people interact (Section 4.2.2). In the latter, the context manifested is sometimes institutional, sometimes non-institutional, and the speakers often have a first language in common.

4.2.1. Language choice and situational context. During seminars, participants with different first languages interact. In two recurring types of situations especially in this context, Swedish-speaking students express themselves in Swedish.

The first recurring situation is when a speaker signals an inability to formulate a word or concept in the course language English. These languagerelated episodes (Swain and Lapkin 1998) are interpolated into the institutional interaction and are part of the institutional situational context, in that the overarching aim is still learning and teaching of the course subject. Such episodes are not particularly common on the course, but do occur occasionally. During the nine hours of seminars that I observe, they arise six times.

One such occasion is when CSR (Corporate Social Responsibility), i.e. the ethical, environmental and social responsibility of companies, is being discussed on the basis of the prescribed reading for the day. Roughly half the seminar has passed, and so far the language used has been exclusively English. The first student to speak argues that CSR could be a management idea, as it must be said to constitute a competitive advantage for companies and organizations. The student, referred to here as Elin, ${ }^{2}$ starts off in English (line 3 in the transcript), but soon interrupts herself to point out that she does not know the English word for "compete", whereupon she says the Swedish word and looks up, first at the lecturer and then at her immediate neighbors on either side. Elin's metacomment clearly signals her awareness that she is switching languages and that Swedish is not expected in this context (cf. Gafa- 
ranga and Torras 2001). The three people she looks at respond by giving the English equivalent of the word. Elin confirms that she has heard the word by saying $j a$, the Swedish for 'yes', and then continues in English, repeating "to compete" before giving her reasons. Later in her answer, on line 14, she returns to the word, linking it to the earlier language-related episode by another short $j a$ that marks continued uncertainty about it. Clearly, the student is not entirely comfortable with this new piece of vocabulary. Indeed, this is the only time Elin speaks during the seminar, and I get the impression that she finds it difficult, even unpleasant, to express herself in an English-medium classroom.

(1) "Compete" (0206 v)

$\mathrm{L}=$ Lecturer; $\mathrm{E}=$ Elin; $\mathrm{S} 1$ and S2 $=$ Swedish-speaking students.

1 L: what is it- why would it be a management idea?

$2 \quad(1.2)$

3 E: ${ }^{\circ} \mathrm{e}:{ }^{\circ}(1.0)(($ looking at $\mathrm{S} 1))$ it it can be a way to: $(0.5)>\mathrm{I}$

4 don't know how to say in English< ((turning her head

5 towards lecturer, then towards S1 and S2)) konkurrera compete

$6 \quad(1.4)$

7 S2: co[mpete

8 L: $\quad\left[{ }^{\circ}\right.$ compete $^{\circ}$

9 S1: [compete hh

10 E: ja: ((looking at lecturer)) to compete because now it's yes

11 e:: so yes many f- firms and ( ) between so many

12 things e: (1.4) so ( ) ((waving her hands)) so (0.6)

13 maybe the CSR can be a way for the corporations

14 to: $>j a<$ to compete [with each other

15 L: [m: (1.0) so it's like a competitive

16 advantage

17 E: yes ((nodding)) I think so

When Swedish is used in this way in language-related episodes, there are almost always metacommunicative comments preceding the switch. The comment makes the episode into a kind of linguistic interlude which briefly shifts the focus from the task-related discussion to a language question. But the episode is short, and the interaction does not lose its institutional character. Swedish becomes, rather, a temporary element in the institutional situational context, and as the metacomment is not uncommonly in English everyone present in the room is included in the situation. Interestingly, this never happens with languages other than Swedish during my observations. The exchange students speak only English during lecturer-led teaching and do not use the other unofficial languages as resources in the seminar room. It would of course be possible, say, for a Spaniard to ask other Spanish speakers about 
words or concepts in the same way as the Swedish students do, but this does not happen in any of the courses I have observed.

These brief interpolations of Swedish are basically the only occasions during on-task talk in the seminars when languages other than English occur. Otherwise, students and teachers stick exclusively to English as long as the subject discussed is business studies and as long as the participants have different first languages (cf. [4], however).

Not all sequences during seminars, though, constitute on-task talk. Apart from purely social exchanges, lecturers or students commonly talk about topics relating to the teaching process as such. The lecturer may for example take a roll call or give instructions concerning a forthcoming assignment. Similarly, students may ask the teacher where an exam is to take place or where they can get hold of a prescribed text. Such sequences revolve around and focus on the actual teaching process. To distinguish the situational context these sequences contribute to from on-task and off-task talk, I shall refer to them below as procedure-related talk. They should be regarded as part of the institutional context, but differ from on-task talk in that their topic is not the subject matter being taught, but the teaching process itself.

In procedure-related talk, students sometimes speak Swedish. On each occasion, use of that language is initiated by a student, usually with a question to the lecturer relating to the teaching. This is the second type of recurring situation in which students speak Swedish in the seminar room, and one that I will discuss below. The alternation of languages serves as one contextualization cue — of several — signaling the new interactional context (cf. Gumperz 1982).

Perhaps the most interesting thing about these situations is that exchange students with no knowledge of Swedish are present in the room. The example below illustrates such a situation. All the students are seated at their desks in the seminar room. It is towards the end of the session, and the lecturer has just given the students the task of formulating a question about the topic they have found most difficult in today's seminar. She is standing at the blackboard addressing the students, who sit silently, with their attention focused on her. One student, referred to here as Einar, interrupts her and asks in Swedish whether this assignment is for today or for the whole course.

(2) "For the whole course?" (0206 v)

$\mathrm{L}=$ Lecturer; $\mathrm{E}=$ Einar.

1 L: so (0.4) now we have: ((looks at her

2 watch)) (1.0) almost twenty minutes or

3 we have fifteen minutes (0.6) e: I would

4 like you to just (0.4) in your group three

5 and three find out (0.6) together the

6 trickiest question that you have the 
question that you really ((making sweep-

8 ing gesture with hand)) need an answer

9 on now (0.4) so we have some time to

$10 \quad(0.5)$ di[scuss di- scuss it a group

11 E: [för hela kursen?

12 L: ((turning to Einar)) ha?

$13 \quad[(($ students in class start talking $))$

14 E: [för hela kursen eller bara det här?

15 L: nej bara-for today (.) so just take like

$16 \quad(0.3)$ three four minutes and find

17 ((waving her hands)) one question that

18 you like to raise in the class $(0.5)$ okay?

for the whole course?

for the whole course or just this one? no only

The dialogue here creates a procedure-related situational context. By what she says, the lecturer sets and structures the assignment. The focus is not on the subject matter of the course as such, but on how an institutional task is to be performed, and Einar asks a question seeking clarification on this. As the transcript shows, he asks his question twice before the lecturer replies. Immediately after the first time of asking, some of the students begin to chat quietly to one another in side activities. Whatever they are talking about, by chatting among themselves they are turning their attention away from the question and the subsequent instructions; i.e. they are treating the sequence in Swedish as unimportant for the class as a whole. The lecturer translates her answer into English and thus once again includes the exchange students in the discussion. By switching languages, she shows that her linguistic obligations in the classroom are different from those of the students.

4.2.2. Language choice and participation. On a number of occasions during the course, students and lecturers form spontaneous groupings. This happens, for example, before and after seminars and during breaks. In these groups, the course language English is rarely used. Nor is use of the lingua franca of the course always communicatively necessary; contact between international and Swedish students is limited and the groups formed tend to consist of individuals from the same country. Swedish-speaking students who already know each other, in particular, often sit on their own.

As a result of these spontaneous groupings, French, Spanish, English and Swedish can all be heard in the seminar room. But multilingual interactional situations rarely arise, as the groups are monolingual. They result, rather, in what could be described as parallel discussions in different languages.

One type of spontaneous group discussion that recurs is when the lecturer instructs the students to spend a few minutes discussing a question with their immediate neighbors before it is considered by the class as a whole. Students 
may, for instance, be asked to talk about CSR in such groups, as happens just before the earlier-quoted switch to Swedish (see [2]). On that occasion, the students form three groups consisting entirely of Swedish speakers, four comprising both exchange and Swedish students, and one made up entirely of exchange students. The first of these discuss the lecturer's questions in Swedish, the others in English. During the quarter of an hour that the discussions last, both languages are heard in the room. The interaction in the groups is institutional as long as the participants are dealing with the task assigned to them.

During these group sessions, students also talk about other topics besides business studies. When they are discussing CSR, for example, one of the most active and ambitious Swedish-speaking students takes the opportunity to hand in the written assignment which all the students have had to prepare before the seminar. The lecturer answers her in Swedish: "perfekt (pause) bäst att jag samlar in dom annars kommer jag att glömma bort det" [perfect (pause) I'd better collect them in otherwise I'll forget]. The sequence consists of social talk and takes place in Swedish, in parallel with the group discussions in the seminar room.

After this brief dialogue, the lecturer collects the other students' texts. As she walks around the room, she is stopped by another Swedish-speaking student, referred to here as Elias, who asks a question. He has arrived late and wants to know what the group assignment is about. He is sitting next to three exchange students (two from Spain and one from Canada) and ought to form a discussion group with them, but does not seem to understand that this is the lecturer's intention. The following transcript presents the dialogue that ensues:

(3) Elias' question (0206 v)

$\mathrm{L}=$ Lecturer; $\mathrm{E}=$ Elias; $\mathrm{X} 1$ and $\mathrm{X} 2=$ exchange students.

1 E: ((raising his hand)) ursäkta? excuse me?

2 L: $\mathrm{m}(($ walking towards E))

$3 \quad(2.8)$

4 E: jag tror jag sabba: ordningen här lite I think I've messed things up here a bit

$5 \quad$ grann genom att komma sent ((L leans

6 over E)) men (0.6) hur gör vi nu för det

7 verkar som att allihop sam-har samlats $i$

8 tregrupper

$9 \quad$ L: $\quad$ ja precis ((straightening up)) (0.4) so if

10 you could form a group of three (0.4)

11 or are you [four ((looking round))

12 E: [men men ja precis det blir

13 fyra [för by arriving late ((L leans over E)) but (0.6) what do we do now because it looks like everyone is form- has formed groups of three yes exactly

14 L: [a: that's okay

but but yes exactly there are four of us because 
15

16

17 L: >no no no but you can< sit there it's okay

18 E: $j a$

19 X1: ((nods))

20 L: m yeah (0.8) ((turns round. Turns back))

21 so you yeah you got the message what

22 you're supposed to discuss ((pointing to

$23 \mathrm{X} 1)$ ) or

24 X1: ((nods))

25 L: yeah you understood that (0.4) good great

26 E: are we gonna (.) present it orally up

27 there?

28 L: no I'm gonna ask you in groups so you

29

30

3

32

32

33

34

35

36

37

38

can present $(0.8)$ [sitting here $=$

E: $\quad$ groups?

L: =yeah so together you discuss-

$\mathrm{X} 2$ : ( )

L: hm?

X2: the attendance list $(0.4)$ he needs

$\mathrm{L}$ : o yeah I'm gonna give it to him (0.4) no

so just discuss how how you reflected

upon CSR together and then (0.7) we will

discuss it (0.3) yeah ((walks away)) do I have to chase round looking for someone

yes

Talking Swedish to other Swedish-speaking students or to the lecturer in sequences like this is typical of the way languages are used in the course, and in the other five courses included in the project. As the transcript shows, however, the student switches languages during the dialogue. First he speaks Swedish to the lecturer (as far as line 18), and then English. How is this change of language to be understood?

As I see it, the switch is linked to a change of perspective, as Elias moves from an individual to a group perspective (cf. change of footing, Goffman [1981]). When he also includes the exchange students, he switches to the course language English. The individual perspective (down to line 18) revolves around Elias and which group he is to join. He speaks Swedish and acts as if this were a conversation purely between himself and the lecturer, by raising his hand and attracting her attention. He says that he has arrived late and perhaps "messed things up" by sitting down with a group that already includes three people. The content of what he says ("everyone has formed groups of three") marks his distance from the group he is sitting with, and his choice of language (Swedish) excludes the exchange students. 
The lecturer answers Elias in Swedish (line 9), but quickly switches to English. At the same time, she straightens up, physically opening up the interactional space to the exchange students. She addresses the whole group: Elias, the Spaniards and the Canadian. But Elias sticks to his individual perspective. In his reply on lines 12 and 15 ("there are four of us" and "do I have to chase around looking for someone?"), Elias takes himself and the question of which group he is to be part of as his starting point. Only after several explanations and after one of the exchange students has also welcomed him into the group (line 19) does Elias accept that he can join it. His acceptance, and his adoption of the perspective of the group, is made clear by his question on line 26: "are we gonna present it orally up there?" Elias now speaks the group language English, uses the pronoun "we" and thus associates himself with the group linguistically.

This example shows how, through various linguistic resources, students and teachers are able to express roles and aims in the potentially multilingual classroom. Elias speaks Swedish when he addresses the lecturer from an individual standpoint (lines 1-18), but English when he talks to her as a representative of the group (lines 19-38) and when he asks how the group is to function. The change of language thus also becomes a way for the participants to handle their participation in the situation and to signal the participant roles of the other people present. Individual multilingualism becomes a resource for the students in an international classroom. In the course studied here, this is particularly true of the home students. Owing to the special position of Swedish, they can use their first language in communication both with the lecturer and with the majority of their fellow students.

\section{Discussion: three competing points of reference}

The examples above illustrate situations in the course where languages other than English occur. As we have seen, English is the language that is used in most contexts, in both on-task and off-task talk, when students or lecturers of different nationalities interact. But Spanish, French and Swedish are also spoken in connection with teaching. Among these unofficial languages, the national language Swedish holds a special position. Swedish is the first language not only of the majority, but also of the lecturers, giving it a privileged place in the classroom.

Below, I discuss what norms and principles the participants orient to in the language choices characterizing the course studied. The discussion and the conclusions reached are based on my ethnographic observations of the course and my linguistic analysis of the video recordings. In broad terms, it is possible to speak of three competing points of reference for language choice in the 
course: (a) English as a lingua franca, (b) the speaker's orientation to her or his own first language, and (c) the special position of the national language, as the first language of the majority and the lecturer.

\subsection{Lingua franca and the speaker's first language}

The first two points, English as a lingua franca (a) and the orientation of speakers to their own first language (b), are reflected in the way students and staff speak English with participants from other countries, but their own language with fellow native speakers of that language. In both cases, the choice of language represents an accommodation to the linguistic proficiency of the other participants. A Swedish-speaking student, for example, generally speaks English to Spanish and French students, but Swedish to other Swedish-speaking students and lecturers. English is thus a de facto lingua franca of the course studied, and its function as a contact language is more important than its status as the nominal language of the course.

This pragmatic approach, which is also observed by Ljosland (2008), seems to have its basis in a practice of taking the "path of least linguistic resistance". Students and teachers choose the language that seems most natural in relation to the roles and aims the interaction revolves around, but also in relation to their own and other participants' language skills. But can the linguistic environment as a whole be said to be multilingual? As has been shown, languages other than English are rarely used in seminars, but frequently in monolingual discussions between individuals with the same first language. This is particularly clear in the case of French and Spanish, which are never used other than in discussions among native speakers of those languages. What we find in this course is thus a parallel, rather than a shared, multilingualism.

\subsection{Special position of the national language}

Besides the course language English, the national language Swedish, as we have seen, holds a special position in the course (point [c] above). All participants, regardless of nationality, handle the language of the surrounding society differently from the other unofficial languages.

The biggest difference is that Swedish is used in contexts where participants with no knowledge of it are present, which means that the speakers temporarily fail to orient to the linguistic proficiency of the other participants (points [a] and [b] above). As noted, the national language occurs during on-task talk in seminars, when Swedish-speaking students lack the necessary English vocabulary (see [1]), and also in situational contexts that are primarily procedure- 
related (see [2]). It is chiefly in the latter that extended sequences in Swedish occur, suggesting a sensitivity on the part of the Swedish-speaking students to the degree of institutionality of the situation. Swedish becomes one of several contextualization cues for procedure-related talk. Such sequences, however, are poorly integrated into the teaching situation, presumably owing precisely to the choice of language.

As I see it, the use of Swedish in procedure-related talk is a reflection of the orientation of speakers towards using their own first language, i.e. point (b) above, and of the tendency to take the path of least linguistic resistance. Because these are characteristics shared by all course participants, regardless of nationality, the international students also accept the use of Swedish in such sequences. A necessary condition for their doing so is probably that Swedish is the first language of the majority and of the lecturer. The latter's knowledge of Swedish is particularly important, as it gives the language a link to the institutional context. All the same, it should be noted that all the students - including those from abroad - are involved in maintaining the special position of Swedish. By not protesting when their Swedish-speaking peers express themselves in that language, the foreign students are partly responsible for its continued use in procedure-related situational contexts.

\subsection{A local norm}

Students and staff, then, have developed a local norm that allows languages other than the course language English to be used during seminars. At first sight, the norm governing the use of different languages in the course seems confused. Fundamentally, though, it is not all that surprising. Examining its first component, namely that language use should be adapted to the participants and their linguistic proficiency, and the second, that it should be adapted to the situation, we find that they agree with basic sociolinguistic principles. In other social contexts, too, participants in interaction tend to converge linguistically as part of the social game, and it is common knowledge that language and context exert a mutual influence. Gafaranga and Torras (2001), for example, show that bilingual speakers negotiate the choice of medium in the course of their interaction and subsequently adopt one and the same medium. In the context of communication accommodation theory, Giles and Coupland (1991) have found that speakers either converge towards or diverge away from one another linguistically as a means of showing social proximity or distance. The local norm which the students and lecturers in our business studies course have developed is thus by no means unique to an international university, but rather reflects basic sociolinguistic points of reference for both monolingual and bilingual interaction. 


\subsection{Challenging the norm}

What happens, then, if someone challenges the norm; i.e. speaks a language other than English in a situational context involving on-task talk, with participants of several nationalities?

The course studied provides an example of how participants explicitly maintain the prevailing norm relating to language use in the course. This happens when the lecturer and the students are discussing, in the seminar room, a concept from a prescribed text. The concept is "dramatization", and a Swedishspeaking student asks the lecturer out loud in English, in front of the entire group, how it is to be understood. The transcript below begins with the lecturer throwing the question back to the students and asking if anyone has any suggestions. One student, referred to here as Erik, raises his hand to reply. In the ensuing dialogue between Erik and the lecturer, two Swedish-speaking students and a Canadian exchange student also speak.

(4) "I pass" (0206 v)

$\mathrm{L}=$ Lecturer; $\mathrm{E}=$ Erik; S1 and S2 = Swedish-speaking students;

$\mathrm{X}=$ Exchange student.

1 L: okay do anyone have any suggestions?

2 what do Masa Alvares mean with

3 dramatization

$4 \quad(0.8)$

5 L: yeah ((pointing))

6 E: isn't it about ho:w (0.6) management

7 ideas have to be (1.1) e: (1)

8 S2: ((looking at Erik)) embedded in sou:rce?

9 E: ((looks up. Throws himself back in

10 chair)) ( ) ä jag får inte till det på

11 engelska (.) $[e$

12 S1: $\quad\left[{ }^{\circ} \mathrm{m}: \mathrm{hh}^{\circ}\right.$

$13 \quad(3.2)$

14 E: (>jag tror jag väntar $<$ ) jag passar

15 L: $d u$ £passar£

$16 \mathrm{~S} 1:$ ((giggles))

17 E: jag får inte till det på engelska

18 L: jamen (0.2) säg det på svenska då

19 E: de måste dramatisera

20 argumentationsmodellen så att den ska

21 passa [media (.) framställningen

$22 \mathrm{X}: \quad\left[{ }^{\circ} \mathrm{hh} \mathrm{o:::kay}{ }^{\circ}\right.$

oh I can't say it in

English (.) e

I think I'll wait I pass

you pass

I can't say it in English

well then (0.2) say it in Swedish then

they have to dramatize

the argumentation model so that it

fits the media (.) presentation 
L: $\quad m o k e j(0.5)$ so what you're saying is that m okay the rhetoric and the discourse is important in order for management ideas to spread

(.) the management knowledge entrepreneurs ((E leans forward $))>$ if we call them that $<$ they need to presents the idea in a certain way that makes it important for ma- for media to write about it so it fits with the media logic so to say ((18 seconds omitted))

L: so you're saying that (0.7) it's a lot about discourse and rhetoric ${ }^{\circ}$ yeah ${ }^{\circ}$

As the transcript shows, Erik starts to answer the question in English (line 6), but soon breaks off. His self-interruption, the ensuing pause and the hesitation sound indicate that he is having problems. Another student realizes this and, looking at Erik, suggests "embedded in source?" (line 8) in an attempt to help him. Erik does not accept the suggestion, and abandons the answer he has started on. He throws himself back in his chair and says (in Swedish): "I can't say it in English" (lines 10-11). By what he says, his body language and his choice of language, he seems to be actively wanting to leave the interactional space and refrain from giving an answer. A pause of just over three seconds follows. Neither the lecturer nor any other student takes the floor. Erik then indicates a second time, now more directly, that he does not wish to answer (line 14), and explains that it because of his inadequate command of English. The lecturer replies that he should say it in Swedish. The way she begins and ends her turn ("jamen säg det på svenska då" [well then say it in Swedish then]) implies that she regards Swedish as an obvious alternative. That the problem is indeed one of language as Erik says, and not of content, is confirmed by the fact that he now answers the question without further ado. The lecturer confirms his answer with a long reformulation of it in English (beginning on line 23) and also checks that she has correctly understood it (lines 34-35), which seems to stabilize and normalize the situation for the subsequent discussion.

Erik's behavior is interesting, in that he gives the impression that English is the only possible language in this situation. His attitude suggests that the linguistic form is more important than the content and that, as a student, it is better to leave a question unanswered than to depart from the lingua franca of the course. The norm is also enforced in this example by other students in the room. S1, who asked the question, giggles when Erik says that he passes 
(line 16), and the exchange student, who has throughout been more active in the seminar room than Erik, says "okay" with a prolonged opening vowel (line 22). It is hard to tell whether Erik hears the Canadian's comment, but S1's reaction is a sufficient indication that he is violating the norm by speaking Swedish in on-task talk. This example is particularly interesting in contrast to earlier ones, in which Swedish-speaking students use Swedish in procedurerelated sequences without any attention being drawn to their choice of language by the other students present. This confirms that different norms apply in these different situational contexts.

It is also clear that it is primarily the students who maintain the norm. The teaching staff have a different attitude towards it. In the sequence above, it is the lecturer who encourages and persuades Erik to depart from the course language English, while Erik himself is hesitant about speaking Swedish. He does not use that language for on-task talk until the lecturer suggests that he should reply in Swedish. The norm requiring English to be spoken in on-task talk with international participants is thus mainly upheld by the students, while the lecturer is less interested in norm-enforcing behavior. The same order of priorities is reflected in the snapshot picture that introduced this article. For the teachers, the linguistic form is of less significance, so long as the students give a correct account of the subject matter of the course.

Pragmatic attitudes to language use thus seem to differ between lecturers and students and can ultimately be traced to participant roles, social obligations and the expectations arising from them. Thus, as Nevile and Wagner (2008: 168) have also shown, the norm governing the use of English and other languages at international universities cannot be taken for granted or understood in advance.

\section{Conclusion}

This article is about how lecturers and students handle the linguistic situation that arises in a Swedish university course aimed at both domestic and foreign students, with English as the medium of instruction. My analysis of the data shows that other languages besides English are used, and that participants adapt their choice of language to local needs and conditions.

Overall, it is possible to talk of three competing points of reference for language use: (a) English as a lingua franca, (b) the speaker's orientation to her or his own first language, and (c) the special position of the national language. Between them, these points of reference leave room for a pragmatic approach and a practice of taking the "path of least linguistic resistance", with students and teachers adapting their choice of language to the linguistic proficiency of other participants, but also to the degree of institutionality of the interaction. 
The norm is clearly locally based and is maintained in particular by the students who follow the course. The lecturers, for their part, are less interested in questions of norm enforcement, and sometimes encourage Swedish-speaking home students to use Swedish even to talk about course subject matter during seminars. The norms of language use are thus not only dependent on linguistic proficiency and situational context; participant roles, social obligations and the expectations arising from them also influence the use of other languages at an international university.

Although practices and attitudes relating to language in international university courses have common points of departure (cf. Nevile and Wagner 2008; Ljosland 2008), more questions need to be answered if we are to fully understand language practices at international universities. What, for example, do linguistic practices and norms look like in classrooms where no specific language group predominates? Does the national language still hold a special position, or are other languages dominant? And what happens if the lecturer speaks a different language from the majority of the students? Individual students and teachers play a major part in shaping the linguistic environment that arises and the norms that develop in teaching. As has been pointed out, internationalization is a dynamic process, and the scope for social and linguistic variation is wide.

Malmö University

Correspondence address: hedda.soderlundh@mah.se

\section{Appendix}

For transcription conventions, see Hutchby and Wooffitt (1998). The transcripts show only the beginning of overlapping speech. As regards intonation, only rising inflection is marked, by the symbol ?. Laughter is indicated by the symbol $£$.

(0.5) Pauses measured in tenths of a second

(.) Pauses of less than (0.2) seconds

$=\quad$ An utterance followed by an equals sign is latched immediately to the following utterance marked by an equals sign with no pause

[ Simultaneous utterances and/or overlaps

hh Audible aspiration

(( )) A description enclosed in a double bracket indicates a non-verbal activity

word- A dash indicates the sharp cut-off of the prior word or sound 
wo:rd Colon indicate that the speaker has stretched the preceding sound or letter

( ) Unclear fragment on the tape

(word) The words within a single bracket indicate the transcriber's best guess at an unclear utterance

? $\quad$ Rising inflection

word Produced with emphasis

${ }^{\circ}$ word $^{\circ}$ Produced more quietly than the surrounding talk

WORD Produced louder than the surrounding talk

$>$ word $<$ Produced noticeably quicker than the surrounding talk

$£$ word£ Produced with laughter

\section{Notes}

1. The usefulness of that figure is unclear, however, as there is no indication of how many of those courses and programs were actually run.

2. In the transcripts I have given names only to the students who initiate the use of Swedish. Other Swedish-speaking students are abbreviated "S" and exchange students " $\mathrm{X}$ ".

\section{References}

Airey, John. 2009. Science, language, and literacy: case studies of learning in Swedish university physics. Uppsala dissertations from the faculty of Science and Technology 81. Uppsala: Acta universitatis upsaliensis.

Auer, Peter. 1995. The pragmatics of code-switching: a sequential approach. In Lesley Milroy \& Pieter Muysken (eds.), One speaker, two languages. Cross-disciplinary perspectives on codeswitching, 115-135. Cambridge: Cambridge University Press.

Björkman, Beyza. 2010. Spoken lingua franca English at a Swedish technical university: An investigation of form and communicative effectiveness. PhD thesis. Stockholm: Department of English, Stockholm University.

Blommaert, Jan. 2007. On scope and depth in linguistic ethnography. Journal of Sociolinguistics 11(5): 682-688.

Bull, Tove. 2006. Latin og engelsk som akademiske lingua francaer [Latin and English as academic lingua francas]. Sprogforum 36: 23-27. http://www.dpu.dk/everest/Publications// udgivelser/forlag/sprogforum/20070430113725/currentversion/sprogforum_36.pdf (accessed 18 December 2009).

Coleman, James A. 2006. English-medium teaching in European higher education. Language Teaching 39. 1-14.

Creese, Angela. 2008. Linguistic ethnography. In Kendall A. King \& Nancy H. Hornberger (eds.), Encyclopedia of language and education, 2nd edn., Vol. 10, Research methods in language and education, 229-241. New York: Springer Science.

Drew, Paul \& John Heritage. 1992. Analyzing talk at work: an introduction. In Paul, Drew \& John Heritage (eds.), Talk at work: interaction in institutional settings, 3-65. Cambridge: Cambridge University Press. 
En högskola i världen - internationalisering för kvalitet [Higher education in the world internationalization for quality]. 2008. Swedish national agency for higher education. 2008: $15 \mathrm{R}$.

Gafaranga, Joseph. 2007. Code-switching as a conversational strategy. In Peter Auer \& Li Wei (eds.), Handbook of multilingualism and multilingual communication, 279-314. Berlin \& New York: Mouton de Gruyter.

Gafaranga, Joseph \& Maria-Carme Torras i Calvo. 2001. Language versus medium in the study of bilingual conversation. International Journal of Bilingualism 5(2): 195-219.

Giles, Howard \& Nikolas Coupland. 1991. Language: Contexts and consequences. Milton Keynes: Open University Press.

Goffman, Erving. 1981. Forms of talk. Philadelphia: University of Pennsylvania Press.

Graddol, David. 2006. English next. English in higher education. London: British council.

Gumperz, John J. 1982. Discourse strategies. Cambridge: Cambridge University Press.

Haberland, Hartmut, Janus Mortensen, Anne Fabricius, Bent Preisler, Karen Risager \& Susanne Kjærbeck (eds.). 2008. Higher education in the global village. Cultural and linguistic practices in the international university. Roskilde: Roskilde University, Department of Culture and Identity.

Hutchby, Ian \& Robin Wooffitt. 1998. Conversation analysis. Principles, practices and applications. Oxford: Polity.

Knight, Jane. 1999. Internationalisation of Higher Education. In Quality and internationalisation in higher education, 13-23. Paris: Organisation for Economic Co-operation and Development.

Ljosland, Ragnhild. 2008. Lingua franca, prestisjespråk og forestilt fellesskap: Om engelsk som akademisk språk $i$ Norge. Et kasusstudium i bred kontekst [Lingua franca, prestige language and imagined communities: on English as an academic language in Norway. A case study in its broader context]. Trondheim: Norwegian University of Science and Technology dissertation.

Ljosland, Ragnhild. 2005. Norway's misunderstanding of the Bologna process: when internationalisation becomes anglicisation. Paper presented at the conference Bi- and Multilingual Universities: Challenges and Future Prospects, Helsinki University, 1-3 September. http://imw.ruc.dk// calpiu/calpiu/publicationfiles/Ljosland\%20R\%202005.pdf (accessed 1 September 2009).

Mauranen, Anna. 2003. The corpus of English as lingua franca in academic settings. TESOL Quarterly 37(3). 513-527.

Montgomery, Catherine. 2008. Global futures, global communities? The role of culture, language and communication in an international university. In Hartmut Haberland, Janus Mortensen, Anne Fabricius, Bent Preisler, Karen Risager \& Susanne Kjærbeck (eds.), Higher education in the global village. Cultural and linguistic practices in the international university, 17-34. Roskilde: Roskilde university, Department of Culture and Identity.

Mortensen, Janus. 2010. Epistemic stance marking in the use of English as a lingua franca: a comparative study of the pragmatic functions of epistemic stance marking in problem-solving sequences at student project group meetings, with special emphasis on meetings where English is used as a lingua franca. Roskilde: Department of Culture and Identity, Roskilde University $\mathrm{PhD}$ thesis.

Nevile, Maurice \& Johannes Wagner. 2008. Managing languages and participation in a multilingual group examination. In Hartmut Haberland, Janus Mortensen, Anne Fabricius, Bent Preisler, Karen Risager \& Susanne Kjærbeck (eds.), Higher education in the global village. Cultural and linguistic practices in the international university, 149-174. Roskilde: Roskilde University, Department of Culture and Identity.

Rampton, Ben. 2007. Neo-Hymesian linguistic ethnography in the United Kingdom. Journal of Sociolinguistics 11(5). 584-607.

Roberts, Celia. 2008. Introduction. In Hartmut Haberland, Janus Mortensen, Anne Fabricius, Bent Preisler, Karen Risager \& Susanne Kjærbeck (eds.), Higher education in the global village. 
Cultural and linguistic practices in the international university, 7-16. Roskilde: Roskilde University, Department of Culture and Identity.

Salö, Linus. 2010. Engelska eller svenska? En kartläggning av språksituationen inom högre utbildning och forskning [English or Swedish? A survey of language use in higher education and research]. (Rapporter från Språkrådet 1.) Stockholm: Språkrådet.

Swain, Merrill \& Lapkin Sharon. 1998. Interaction and second language learning: Two adolescent French immersion students working together. The Modern Language Journal 82(3). 320-337.

Söderlundh, Hedda. 2010. Internationella universitet - lokala språkval. Om bruket av talad svenska i engelskspråkiga kursmiljöer [International universities — local language choices. On spoken Swedish in English-medium course environments]. (Skrifter utgivna vid Institutionen för nordiska språk 83.) Uppsala: Uppsala University, Department of Scandinavian Languages.

Utländska studenter i Sverige [Foreign students in Sweden]. 2008. Swedish national agency for Higher Education. 2008: 7 R.

Wächter, Bernd \& Maiworm, Friedhelm. 2008. English-taught programmes in European higher education. The picture in 2007. (ACA Papers on International Cooperation in Education). Bonn: Lemmens. 
Unauthenticated | 195.178.225.190 Download Date | 11/9/12 11:39 AM 